\title{
Mapeamento de locos de características quantitativas no cromossomo 6, associados às características de carcaça e de órgãos internos de suínos ${ }^{1}$
}

\author{
Aldrin Vieira Pires ${ }^{2}$, Paulo Sávio Lopes ${ }^{3}$, Simone Eliza Facioni Guimarães ${ }^{3}$
}

\author{
1 Parte da tese de Doutorado do primeiro autor. \\ 2 Departamento de Zootecnia da Universidade Federal dos Vales do Jequitinhonha e Mucuri, Diamantina, MG, CEP: 39.100-000. \\ ${ }^{3}$ Departamento de Zootecnia da UFV, Viçosa, MG. CEP: 36571-000.
}

RESUMO - Com o objetivo de mapear locos de características quantitativas (QTLs) associados às características de carcaça e de órgão internos, uma população composta de 550 animais $F_{2}$ foi produzida a partir do intercruzamento da geração $F_{1}$, obtida pelo cruzamento divergente de dois machos da raça nativa brasileira Piau com 18 fêmeas comerciais. Os animais foram genotipados para 13 marcadores microssatélites distribuídos no cromossomo 6. As características avaliadas foram: comprimento de carcaça pelos métodos brasileiro e americano, peso e rendimento de carcaça, espessura de toucinho na região da copa, espessura de toucinho imediatamente após a última costela, espessura de toucinho entre a última e a penúltima vértebra lombar, menor espessura de toucinho na região acima da última vértebra lombar, espessura de toucinho imediatamente após a última costela, a $6,5 \mathrm{~cm}$ da linha dorso-lombar, espessura de toucinho média (geral = estimada a partir da média de todas as espessuras de toucinho citadas anteriormente; e dorso-lombar = estimada a partir das espessuras de toucinho tomadas na linha dorso-lombar do animal), espessura de bacon, profundidade de lombo, área de olho-de-lombo, pesos de órgãos internos (coração, pulmões, fígado, baço e rim) e comprimento de intestino. Utilizou-se o método de regressão por intervalo de mapeamento por meio do programa QTL Express. Foram encontrados QTLs sugestivos para as características de comprimento de carcaça pelo método brasileiro e espessura de bacon e QTL significativo para peso do rim. Nos intervalos dos picos da estatística F em que se encontraram QTLs sugestivos, devem ser incluídos mais marcadores para se confirmar a real presença de QTL.

Palavras-chave: QTL, cruzamento divergente, genética molecular, melhoramento animal

\section{Mapping of quantitative trait loci for carcass traits and internal organs in swine chromosome 6}

\begin{abstract}
A total of the $550 \mathrm{~F} 2$ animals produced by divergent cross using two sires of the native Brazilian breed named Piau and 18 commercial dams were genotyped for 13 microsatellite markers in swine chromosome 6 . The traits evaluated were: carcass length by the Brazilian carcass classification method, carcass length by the American carcass classification method, carcass weight, carcass yield, higher backfat thickness at last 2nd-3rd thoracic vertebrae, backfat thickness after last rib, backfat thickness between last 1st-2nd lumbar vertebrae, lower backfat thickness after last lumbar vertebrae, backfat thickness after last rib, at $6,5 \mathrm{~cm}$ from the midline, average backfat thickness (global = estimated by average of all backfat thickness; and midline = estimated by average of midline backfat thickness), bacon depth, loin depth and loin eye area; internal organs weight (heart, lungs, liver, kidney and spleen), and intestine length. Data were analyzed by multiple regression using the interval mapping method from the QTL Express software. Suggestive QTL were found for carcass length by the Brazilian method and bacon depth and a significant one for kidney weight. Additional markers should be included in the peak intervals of the suggestive F-values to confirm the presence of QTL.
\end{abstract}

Key Words: animal breeding, divergent cross, QTL, molecular genetic

\section{Introdução}

Os recentes avanços na pesquisa genômica poderão mudar e melhorar a produção animal nos próximos anos. Mapas de ligação estão sendo desenvolvidos para diversas espécies de interesse econômico e, certamente, o mapa genético dos suínos é um dos mais saturados.
O genoma suíno possui cerca de $2.800 \mathrm{cM}$, distribuídos em 18 cromossomos autossômicos mais os cromossomos sexuais. Este genoma tem aproximadamente 1.000 marcadores genéticos efetivos, o que permite um mapeamento genômico com distância média de aproximadamente $2,8 \mathrm{cM}$ entre marcadores (Roslin Institute, 2003). 
Um dos principais objetivos do mapeamento genômico é a procura por locos de característica quantitativa (QTLs) influenciando as características economicamente importantes na produção animal. Recentemente, a utilização dos marcadores genéticos moleculares tem possibilitado estudar melhor a variação das características quantitativas e a identificação de locos individuais controlando as características de importância econômica.

Os primeiros mapas de ligação para animais domésticos usando marcadores de DNA foram desenvolvidos em 1994 e 1995 em bovinos, suínos e ovinos. Apesar de o número de marcadores ter aumentado muito nos mapas das espécies de interesse econômico, poucos genes foram identificados a partir desses QTLs. Genes não precisam ser identificados para que um QTL seja utilizado na produção animal para melhorar a acurácia da seleção (seleção assistida por marcadores - MAS). Porém, a identificação de genes associados às variações fenotípicas pode melhorar a eficiência da utilização dos marcadores de DNA nas diferentes espécies de animais domésticos (Kappes, 1999).

Entre as estratégias de mapeamento de QTL, a escolha do delineamento para obtenção dos indivíduos que formarão a população a ser genotipada é essencial. A utilização de uma população $F_{2}$, obtida do cruzamento entre raças geneticamente divergentes, apresenta algumas vantagens, como maior facilidade de detecção de QTL e grande segregação de alelos, tendo em vista a maior variabilidade genética. Contudo, quando se utiliza cruzamento entre raças geneticamente divergentes, a aplicação direta à seleção assistida por marcadores deve ser analisada para se verificar em qual raça parental estão os QTLs encontrados.

A maioria dos cruzamentos em suínos para formação de uma população divergente $\mathrm{F} 2$ é obtida pelo acasalamento entre porco selvagem europeu ou porco chinês e animais provenientes de raças comerciais, Landrace, Large White e Pietrain (Roslin Institute, 2003; Rothschild, 2003).

Muitos estudos têm sido voltados para a busca de QTL afetando características de carcaça em suínos (Andersson et al., 1994; Rothschild et al., 1995; Andersson-Eklund etal., 1998; Rohrer \& Keele, 1998; Wang et al., 1998; Nezer et al., 1999; Yu et al., 1999; Rohrer, 2000; Walling et al., 2000; Bidanel et al., 2001; de Koning et al., 1999; Malek et al., 2001, entre outros) e, na maioria, foram encontrados QTLs com efeitos significativos na variação fenotípica das características, ou QTLs com efeitos sugestivos sobre as características estudadas.

As características de carcaça são muito importantes na produção suína, sobretudo aquelas relacionadas a maior rendimento de carne e menor deposição de gordura, para o atendimento ao crescente e cada vez mais exigente mercado consumidor de produtos suinícolas.
Este trabalho foi realizado com o objetivo de mapear, no cromossomo 6 de suínos, QTLs associados às características de carcaça e ao peso de alguns órgãos internos a partir de uma população $\mathrm{F}_{2}$, obtida por cruzamento divergente.

\section{Material e Métodos}

A formação das famílias e a obtenção dos dados fenotípicos foram realizadas na Granja de Melhoramento de Suínos do Departamento de Zootecnia da Universidade Federal de Viçosa (UFV), em Viçosa, MG, Brasil, no período de novembro de 1998 a julho de 2001.

Utilizou-se o delineamento de $F_{2}$ para se obter desequilíbrio de fase de ligação entre os marcadores e os QTLs. Para isso, foram utilizadas duas famílias parentais originadas de raças geneticamente divergentes (piau e comercial). A geração $F_{1}$ foi proveniente do cruzamento de dois machos da raça nativa brasileira Piau com 18 fêmeas de linhagem desenvolvida na UFV pelo acasalamento de animais das raças comerciais Landrace x Large White x Pietrain, selecionadas para características de desempenho. A geração $F_{1}$ nasceu nos meses de março e maio de 1999. Entre os machos $\mathrm{F}_{1}$, foram selecionados ao acaso 11 varrões provenientes de diferentes leitegadas, que foram acasalados (monta natural) com 54 fêmeas. Esses animais foram acasalados nos meses de fevereiro a outubro de 2000 para a produção da geração $\mathrm{F}_{2}$, que nasceu entre junho de 2000 e fevereiro de 2001. Assim, foram obtidos 617 animais (322 machos e 295 fêmeas) $F_{2}$, distribuídos em cinco lotes ( 1 - 124 animais nascidos entre 20/06/00 e 03/07/00;2-154 animais nascidos entre 03/08/00 e 23/08/00; 3 - 92 animais nascidos entre $16 / 09 / 00$ e $01 / 11 / 00 ; 4-118$ animais nascidos entre 30/11/00 e 25/12/00; e $5-129$ animais nascidos entre 19/01/01 e 12/02/01).

Os três primeiros lotes foram constituídos de animais nascidos de matrizes de primeira parição e os demais, de segunda parição.

Os machos foram castrados aos dez dias e todos os leitões foram desmamados aos 21 dias de idade. $\mathrm{O}$ abate foi realizado (após jejum alimentar de 18 horas, com livre acesso à água fresca) na própria granja em que os animais foram criados, à medida que atingiram $65 \mathrm{~kg}$ de PV (média de 64,84 kg e desvio-padrão de $5,53 \mathrm{~kg}$ ) e cerca de 148 dias de idade (média de 147,83 dias e desvio-padrão de 9,95 dias).

$\mathrm{Na}$ geração $\mathrm{F}_{2}$, foram avaliadas as seguintes características na meia-carcaça esquerda: comprimento de carcaça pelos métodos brasileiro (MBCC) e americano (MLC); peso de carcaça com cabeça e pés (PCARC), rendimento de carcaça com cabeça e pés (RCARC), espessura de toucinho nas posições ETSH (maior espessura de toucinho na região 
da copa, na linha dorso-lombar), ETUC (espessura de toucinho imediatamente após a última costela, na linha dorso-lombar), ETUL (espessura de toucinho entre a última e a penúltima vértebra lombar, na linha dorso-lombar), ETL (menor espessura de toucinho na região acima da última vértebra lombar, na linha dorso-lombar) e P2 (espessura de toucinho imediatamente após a última costela, a $6,5 \mathrm{~cm}$ da linha dorso-lombar). Na meia-carcaça resfriada, na região da última costela, a partir de um corte transversal no carré, mediram-se a ETO (espessura de toucinho, a 6,5 cm da linha dorso-lombar, equivalente à P2) e a PROFLOMB (profundidade de lombo, diâmetro do músculo Longissimus dorsi sobre uma reta traçada da coluna vertebral serrada até a posição onde foi medida a ETO).

Foram estimadas a espessura de toucinho média (ETOM) a partir de todas as espessuras de toucinho citadas anteriormente $[\mathrm{ETOM}=(\mathrm{ETSH}+\mathrm{ETUC}+\mathrm{ETUL}+\mathrm{ETL}+\mathrm{ETP} 2+$ ETO)/6] e a espessura de toucinho média (ETOMDOR) a partir das espessuras de toucinho tomadas na linha dorsolombar do animal $[$ ETOMDOR $=(\mathrm{ETSH}+\mathrm{ETUC}+\mathrm{ETUL}+$ ETL/4]. A área de olho-de-lombo (AOL) foi medida em triplicata (realizou-se a mensuração três vezes e utilizou-se a média), com auxílio de um planímetro, no decalque vegetal tomado da seção transversal do músculo Longissimus dorsi, na altura da última costela, além de espessura do bacon (EBACON), medida imediatamente após a última costela, na altura da divisão carré-bacon.

Foram medidos os pesos de pulmão (PULMAO), coração (COR), fígado (FIG), baço (BACO) e rim (RIM) e o comprimento total do intestino delgado (INTEST). Os números de observações, as médias e os desvios-padrão destas características são apresentados na Tabela 1 .

A análise genotípica foi realizada no Laboratório de Biotecnologia Animal do Departamento de Zootecnia da Universidade Federal de Viçosa. O DNA dos animais parentais foi extraído do sangue dos animais $\mathrm{F}_{1}$ e $\mathrm{F}_{2}$, coletado imediatamente após o abate. As soluções de DNA para uso (na concentração aproximada de $25 \mathrm{~g} / \mathrm{mL}$ ) foram mantidas a $4^{\circ} \mathrm{C}$.

Os primers de microssatélites foram doados pelo Dr. Max F. Rothschild, coordenador do Projeto Genômico Suíno Norte-Americano (Rothschild, 2003).

Tabela 1 - Número de observações, média e desvios-padrão para as características estudadas

Table 1 - Number of observations, average and standard deviations for the traits studied

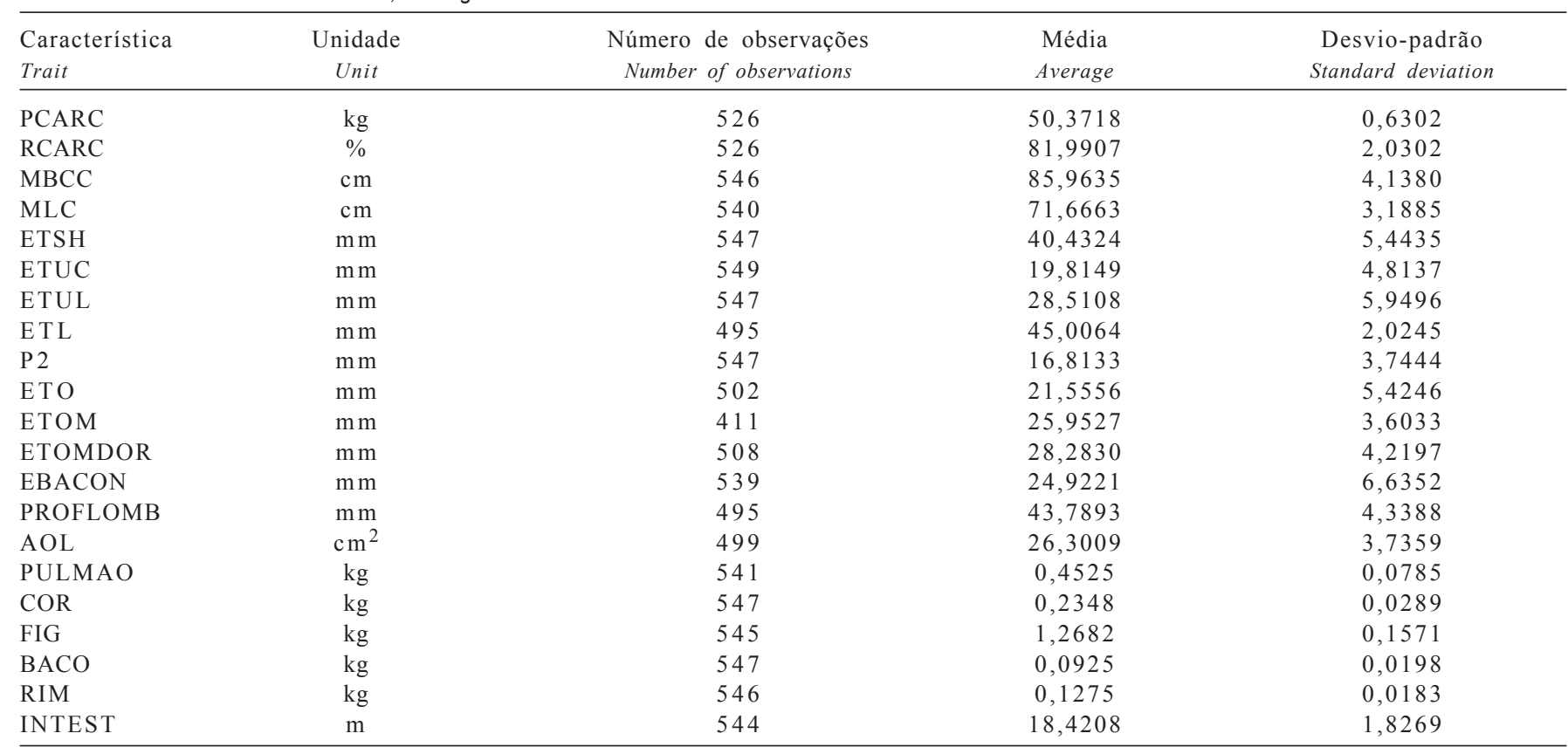

PCARC - peso da carcaça; RCARC - rendimento de carcaça com pés e cabeça; MBCC - comprimento de carcaça pelo Método Brasileiro de Classificação de Carcaça; MLC - comprimento de carcaça pelo Método Americano; ETSH - maior espessura de toucinho na região da copa, na linha dorso-lombar; ETUC espessura de toucinho imediatamente após a última costela, na linha dorso-lombar; ETUL - espessura de toucinho entre a última e a penúltima vértebra lombar, na linha dorso-lombar; ETL - menor espessura de toucinho na região acima da última vértebra lombar, na linha dorso-lombar; P2 - espessura de toucinho medida imediatamente após a última costela, a $6,5 \mathrm{~cm}$ da linha dorso-lombar; ETO - espessura de toucinho a $6,5 \mathrm{~cm}$ da linha dorso-lombar; equivalente à P2; ETOM - espessura de toucinho média; ETOMDOR - espessura de toucinho média entre as espessuras dorso-lombar; EBACON - espessura do bacon; PROFLOMB - profundidade de lombo; AOL - área de olho de lombo; PULMAO - peso de pulmão; COR - peso de coração; FIG - peso de fígado; BACO - peso de baço, RIM - peso de rim e INTEST - comprimento total do intestino delgado.

PCARC - carcass weight; RCARC - carcass yield with feet and head; MBCC - carcass length by the Brazilian carcass classification method; MLC - carcass length by the American carcass classification method; ETSH - higher backfat thickness at last 2nd-3rd thoracic vertebrae; ETUC - backfat thickness afterlast rib; ETUL - backfat thickness between last 1 st-2nd lumbar vertebrae; $E T L$-lowerbackfat thickness afterlastlumbarvertebrae; $P 2$ backfat thickness after last rib, at $6,5 \mathrm{~cm}$ from the midline; $E T O$ - backfat thickness at $6,5 \mathrm{~cm}$ from the midline; equivalent to $P 2 ; E T O M$ - average backfat thickness estimated by average of all backfat thickness; ETOMDOR-average backfat thickness estimated by average of midline backfat thickness; EBACON - bacon depth; PROFLOMBloin depth; AOL - loin eye area; PULMAO - lungs weight; COR - heart weight; FIG - liver weight; BACO - kidney weight RIM - spleen weight and INTEST - intestine length. 
Foram utilizados primers para cobrir o cromossomo 6 de suínos a um intervalo médio de $12,7 \mathrm{cM}$. Na Tabela 2 são apresentados os primers com algumas características específicas, como localização, fluorescência, faixa da variação de tamanho, em pares de base (pb), e número de alelos.

Para as amplificações, foram utilizados os termocicladores MJ Reseach, Inc. modelo PTC-100/96. As reações foram constituídas de Taq polimerase $1 \mathrm{U}$, dNTPs $0,2 \mathrm{mM}$, primers foward e reverse $0,2 \mu \mathrm{M}$ cada, Tris- $\mathrm{HCl} \mathrm{pH}$ $8,320 \mathrm{mM}, \mathrm{KCl} 50 \mathrm{mM}$. As concentrações de $\mathrm{Mg}$ variaram de 2 a $43 \mathrm{mM}$ em função do padrão de amplificação dos primers. Foram utilizados $25 \eta$ g de DNA genômico por reação, em um volume final de $10 \mu \mathrm{L}$.

O padrão de amplificação dos marcadores foi inicialmente observado em gel de poliacrilamida a 5\%, aplicando-se $5 \mu \mathrm{L}$ de cada reação. Após a corrida em cuba de eletroforese, foi realizada a coloração com nitrato de prata. Confirmadas as amplificações, os produtos foram congelados a $-20^{\circ} \mathrm{C}$ para posterior análise dos fragmentos. Estas análises foram feitas por meio de eletroforese em géis de poliacrilamida a $5 \%$, utilizando-se seqüenciador automático ABI Prism 377.

A detecção e discriminação dos fragmentos polimórficos amplificados foram feitas utilizando-se o programa GenScan. Posteriormente, os dados foram extraídos e convertidos em um arquivo de saída pelo programa Genotyper v.2.0, ambos da Applied Biosystems.

As distâncias de consenso do mapa de ligação de suínos são apresentadas na Tabela 2. O mapeamento de QTL foi realizado pelo programa QTL Express (Seaton et al., 2002), que emprega o método de regressão por intervalo de mapeamento desenvolvido para análises de cruzamentos entre raças divergentes (Haley et al., 1994).
No modelo estatístico, assume-se que o QTLé dialélico, com alelos alternativos fixados em cada raça parental (Haley et al., 1994). Considerou-se o genótipo QQ para os animais comerciais, com efeito a, qq para os animais nativos, com efeito -a, e Qq para os animais $\mathrm{F}_{1}$, com efeito d. A probabilidade de cada indivíduo F2 apresentar cada um dos três genótipos do QTL é calculada condicionalmente aos marcadores, a intervalos de $1 \mathrm{cM}$ ao longo do cromossomo. Essas probabilidades são usadas para se fazer a regressão das características em função dos efeitos genéticos aditivos e de dominância do QTL em estudo para cada animal.

Os valores da estatística $\mathrm{F}$ foram plotados e os pontos com os maiores valores para a estatística do teste foram apresentados como a possível posição do provável QTL (Seaton et al., 2002). Os níveis de significância ( $\alpha=0,10,0,05$ ou 0,01 ) ao longo do cromossomo foram obtidos pelo teste de permutação (Churchill \& Doerge, 1994), utilizando-se um total de 10.000 permutações para cada característica. O teste de permutação foi executado pelo programa QTL Express (Seaton et al., 2002) e, posteriormente, foi utilizado o "Proc Univariate" do SAS (SAS, 1990) para obtenção dos níveis de significância a 1 e 5\% (QTL significativo) e a 10\% (QTL sugestivo) de probabilidade, a partir das informações de todas as características simultaneamente.

Foi adotado o seguinte modelo estatístico:

$$
y_{i j k}=S_{i}+L_{j}+\left(C_{i j k}-\bar{C}\right) \beta+c_{a} a+c_{d} d+e_{i j k}
$$

em que: $y_{i j k}=$ fenótipo; $S_{i}=$ efeito fixo do sexo $\mathrm{i}, \mathrm{i}=1$ (macho), 2 (fêmea); $L_{j}=$ efeito fixo do lote $\mathrm{j}, \mathrm{j}=1,2,3,4,5$; $\left(C_{i j k}-\bar{C}\right) \beta=$ ajustamento para a covariável peso de carcaça quente; $\mathrm{C}_{\mathrm{ijk}}=$ peso da carcaça do animal $\mathrm{k}$, do sexo $\mathrm{i}$, pertencente ao lote $\mathrm{j} ; \overline{\mathrm{C}}=$ peso médio da carcaça; e $\beta=$ coeficiente de regressão linear do peso da carcaça quente.

Tabela 2 - Primers utilizados na varredura do cromossomo 6 de suínos Table 2 - $\quad$ Primers used to scan the swine chromosome 6

\begin{tabular}{|c|c|c|c|c|c|}
\hline $\begin{array}{l}\text { Marcador } \\
\text { Marker }\end{array}$ & $\begin{array}{l}\text { Posição }^{1}(\mathrm{cM}) \\
\text { Position }(c M)\end{array}$ & $\begin{array}{l}\text { Temp. anel. }{ }^{2} \\
\text { Temp. anneal. }\end{array}$ & $\begin{array}{l}\text { Mínimo alelo }(\mathrm{pb}) \\
\text { Minor allele }(p b)\end{array}$ & $\begin{array}{l}\text { Máximo alelo }(\mathrm{pb}) \\
\text { Major alelle }(p b)\end{array}$ & $\begin{array}{l}\text { Número de alelos } \\
\text { Number of alleles }\end{array}$ \\
\hline S0035 & 7,3 & 62 & 178 & 186 & 4 \\
\hline SW 1353 & 29,2 & 58 & 154 & 168 & 4 \\
\hline SW 1841 & 41,5 & 58 & 175 & 236 & 7 \\
\hline SW 1057 & 47,1 & 56 & 150 & 188 & 7 \\
\hline DG94 & 93,0 & 56 & 174 & 190 & 4 \\
\hline S0003 & 102,0 & 56 & 131 & 162 & 6 \\
\hline S0228 & 105,2 & 56 & 221 & 241 & 5 \\
\hline SW 1881 & 121,1 & 58 & 151 & 183 & 5 \\
\hline SW 1680 & 153,9 & 65 & 118 & 158 & 7 \\
\hline SW607 & 165,7 & 56 & 152 & 172 & 3 \\
\hline
\end{tabular}

\footnotetext{
1 Segundo Rothschild (2003), ${ }^{2}$ Temperatura de anelamento em ${ }^{\circ} \mathrm{C}$.
}

${ }^{1}$ According to Rothschild (2003); ${ }^{2}$ Temp. anneal = annealing te $\mathrm{mperature} \mathrm{in}{ }^{\circ} \mathrm{C}$. 
$\mathrm{C}_{\mathrm{a}}$ e $\mathrm{C}_{\mathrm{d}}=$ coeficientes dos efeitos genotípicos aditivos (a) e de dominância (d), respectivamente, foram calculados da seguinte forma:

$$
\begin{gathered}
c_{a}=P(Q Q)-P(q q) \\
c_{d}=P(Q q)
\end{gathered}
$$

em que: $\mathrm{P}(\mathrm{QQ})$ = probabilidade de os alelos do $\mathrm{QTL}$ serem homozigotos com origem comercial; $\mathrm{P}(\mathrm{qq})=$ probabilidade de os alelos do QTL serem homozigotos com origem nativa; $\mathrm{P}(\mathrm{Qq})=$ probabilidade de os alelos do QTL serem heterozigotos.

O modelo anterior foi utilizado para estimativa da regressão do fenótipo em função dos coeficientes e, variando a posição do QTL a cada cM. Para cada posição, foi calculada uma estatística F, comparando o modelo que considera a presença do QTL (modelo completo) ao modelo sem o QTL (modelo reduzido). As estimativas para a e d foram calculadas como a melhor posição estimada com o maior valor da estatística F correspondente.

\section{Resultados e Discussão}

Na Tabela 3 é apresentado um resumo das estatísticas F máximas, suas posições (cM) para os prováveis QTLs e as estimativas dos efeitos aditivos e de dominância, com os respectivos erros-padrão.

Nas Figuras 1, 2, 3, 4 e 5, constam as distribuições das estatísticas $\mathrm{F}$ ao longo do cromossomo, sendo que os picos das curvas indicam as posições, em cM, onde os prováveis QTLs estão localizados.

Detectou-se (Tabela 3 e Figura 1) um QTL sugestivo $(\mathrm{P}<0,10)$ para comprimento de carcaça pelo método brasi- leiro $(\mathrm{MBCC})$ apresentando um $\mathrm{F}_{\max }=5,25$ na posição de 7 cM. No entanto, não houve evidência de QTL para comprimento de carcaça pelo método americano (MLC).

O QTL sugestivo para comprimento de carcaça pelo método brasileiro (MBCC) encontrado a $7 \mathrm{cM}$ no cromossomo 6 (SSC6) é indicativo de que há locos associados ao tamanho corporal e, conseqüentemente, locos para taxa de crescimento. No entanto, como se trata de QTL sugestivo, pode-se saturar mais o mapa de ligação nesta região para se investigar a real existência deste QTL. Cabe ressaltar também que a magnitude dos efeitos aditivos $[0,4666(0,2985)]$ e de dominância [-1,2977 (0,4333)] deste QTL sugestivo não apresenta muita precisão, o que pode ser comprovado pelos respectivos erros-padrão das estimativas. Diversos autores encontraram QTLs com efeito significativo para comprimento de carcaça em outros cromossomos: no 7 (Nezer et al., 2002; Rohrer \& Keele, 1998), no 8 (Andersson-Eklund et al., 1998) e nos cromossomos 6, 11 e X (Malek et al., 2001).

As características peso (PCARC) e rendimento de carcaça (RCARC) não apresentaram valores da estatística F significativos, não havendo, portanto, indícios da presença de QTLs associados a estas características (Figura 1 e Tabela 3). Rohrer \& Keele (1998) encontraram QTL significativo para peso de carcaça nos cromossomos $3(5 \mathrm{cM})$ e 7 (60 cM); e Malek et al. (2001) detectaram QTL com efeito significativo sobre PCARC no cromossomo $4(123 \mathrm{cM})$.

Estes resultados, diferentes daqueles relatados na literatura para $\mathrm{MBCC}, \mathrm{PCARC}$ e RCARC, podem ter sido ocasionados pela diferença na composição genética entre os indivíduos que compõem a população parental deste estudo,

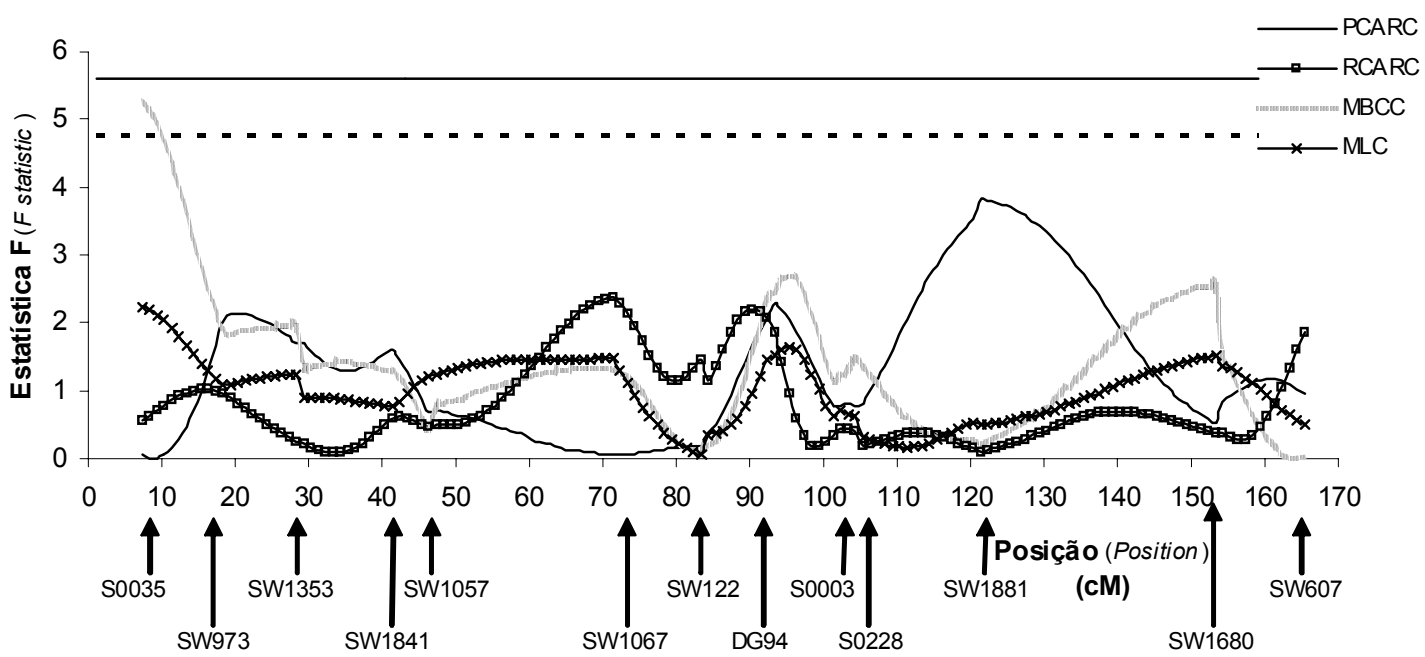

Figura 1 - Estimativas da estatística F para as características peso (PCARC), rendimento de carcaça (RCARC) e comprimento de carcaça pelos métodos brasileiro (MBCC) e americano (MLC). As linhas horizontais indicam os níveis de significância ao longo do cromossomo para QTL significativo ( $5 \%$ = linha contínua) e QTL sugestivo $(10 \%=$ linha tracejada).

Figure 1 - Estimates of F statistic for the traits: PCARC - carcass weight; RCARC - carcass yield with feet and head; MBCC - carcass length by the Brazilian carcass classification method; MLC - carcass length by the American carcass classification method. The horizontal lines indicate the levels of significance along the chromosome for significant QTL (5\% = continuous line) and suggestive QTL $(10 \%=$ dotted line). 
Tabela 3 - Resumo das estatísticas F máximas, com suas posições (cM) para os QTLs, e estimativas dos efeitos aditivos e de dominância Table 3 - Summary of maximum F statistics and their positions (cM) for the QTL and respective estimates of the additive and dominance effects

\begin{tabular}{lrrrr}
\hline Característica & $\begin{array}{r}\text { Posição }(\mathrm{cM}) \\
\text { Position }(\mathrm{cM})\end{array}$ & $\begin{array}{c}\mathrm{F}_{\max } \\
F_{\max }\end{array}$ & $\begin{array}{c}\text { Aditivo }\left(\mathrm{EP}^{1}\right) \\
\text { Additive }\left(E P^{I}\right)\end{array}$ & $\begin{array}{c}\text { Dominância }(\mathrm{EP}) \\
\text { Dominance }(E P)\end{array}$ \\
\hline PCARC & 121 & 3,83 & $-1,0103(0,3849)$ & $-0,1576(0,5904)$ \\
RCARC & 71 & 2,38 & $0,0672(0,4980)$ & $-1,3792(0,6328)$ \\
MBCC & 7 & $\mathbf{5 , 2 5}$ & $0,4666(0,2985)$ & $-1,2977(0,4333)$ \\
MLC & 7 & 2,23 & $0,2967(0,2378)$ & $-0,6329(0,3452)$ \\
ETSH & 154 & 1,56 & $0,7367(0,4408)$ & $0,3580(0,6087)$ \\
ETUC & 92 & 2,62 & $0,1378(0,3745)$ & $-1,2366(0,5408)$ \\
ETUL & 53 & 3,50 & $0,6620(0,5023)$ & $1,7777(0,7949)$ \\
ETL & 61 & 3,46 & $-0,1101(0,5738)$ & $2,2603(0,8596)$ \\
P2 & 70 & 4,38 & $0,1195(0,2941)$ & $1,1296(0,3818)$ \\
ETO & 51 & 2,78 & $0,0038(0,4669)$ & $1,7300(0,7340)$ \\
ETOM & 154 & 2,91 & $0,7945(0,3307)$ & $0,1311(0,4676)$ \\
ETOMDOR & 154 & 2,76 & $0,7867(0,3370)$ & $0,1566(0,4765)$ \\
EBACON & 7 & $\mathbf{4 , 8 8}$ & $-0,3884(0,4295)$ & $1,9493(0,6482)$ \\
PROFLOMB & 110 & 1,93 & $-0,2517(0,4076)$ & $-1,1610(0,6589)$ \\
AOL & 136 & 3,15 & $0,0356(0,3880)$ & $-1,7501(0,7002)$ \\
PULMAO & 29 & 2,33 & $-0,0156(0,0074)$ & $0,0067(0,0116)$ \\
COR & 102 & 2,67 & $-0,0013(0,0022)$ & $0,0072(0,0032)$ \\
FIG & 101 & 2,20 & $0,0232(0,0120)$ & $0,0111(0,0172)$ \\
BACO & 165 & 4,45 & $0,0055(0,0020)$ & $0,0055(0,0031)$ \\
RIM & 75 & $\mathbf{6 , 9 9 *}$ & $0,0049(0,0018)$ & $0,0059(0,0024)$ \\
INTEST & 84 & 2,25 & $0,3352(0,1579)$ & $-0,0413(0,2156)$ \\
\hline
\end{tabular}

*,$\dagger=$ significativo a $5 \%$ e sugestivo a $10 \%$ de probabilidade, respectivamente. ${ }^{1}$ EP = erro-padrão.

Características: PCARC - peso da carcaça; RCARC - rendimento de carcaça com pés e cabeça; MBCC - comprimento de carcaça pelo Método Brasileiro de Classificação de Carcaça; MLC - comprimento de carcaça pelo Método Americano; ETSH - maior espessura de toucinho na região da copa, na linha dorsolombar; ETUC - espessura de toucinho imediatamente após a última costela, na linha dorso-lombar; ETUL - espessura de toucinho entre a última e a penúltima vértebra lombar, na linha dorso-lombar; ETL - menor espessura de toucinho na região acima da última vértebra lombar, na linha dorso-lombar; P2 - espessura de toucinho medida imediatamente após a última costela, a $6,5 \mathrm{~cm}$ da linha dorso-lombar; ETO - espessura de toucinho a $6,5 \mathrm{~cm}$ da linha dorso-lombar, equivalente à P2; ETOM - espessura de toucinho média; ETOMDOR- espessura de toucinho média entre as espessuras dorso-lombar; EBACON - espessura do bacon; PROFLOMB - profundidade de lombo; AOL - área de olho-de-lombo; PULMAO - peso de pulmão; COR - peso de coração; FIG - peso de fígado; BACO - peso de baço; RIM - peso de rim e INTEST - comprimento total do intestino delgado.

${ }^{*}, t=$ Significant at $5 \%$ and suggestive at $10 \%$ probability levels, respectively; ${ }^{1} \mathrm{EP}=$ standard error.

PCARC - carcass weight; RCARC - carcass yield with feet and head; MBCC - carcass length by the Brazilian carcass classification method; MLC - carcass length by the American carcass classification method; ETSH - higher backfat thickness at last $2^{\text {nd }}$ - $3^{\text {rd }}$ thoracic vertebrae; ETUC - backfat thickness afterlast rib; ETUL - backfat thickness between last $1^{\text {st }}$ - $2_{\text {nd }}$ lumbarvertebrae; $E T L$ - lower backfat thickness after last lumbar vertebrae; $P 2$ backfat thickness after last rib, at $6.5 \mathrm{~cm}$ from the midline; ETO - backfat thickness at $6.5 \mathrm{~cm}$ from the midline; equivalent to $P 2$; $E T O M$ - average backfat thickness estimated by average of all backfat thickness; ETOMDOR-average backfat thickness estimated by average of midline backfat thickness; EBACON-bacon depth; PROFLOMB - loin depth; AOL - loin eye area; PULMAO - lungs weight; COR - heart weight; FIG - liver weight; BACO - kidney weight RIM - spleen weight and INTEST - intestine length.

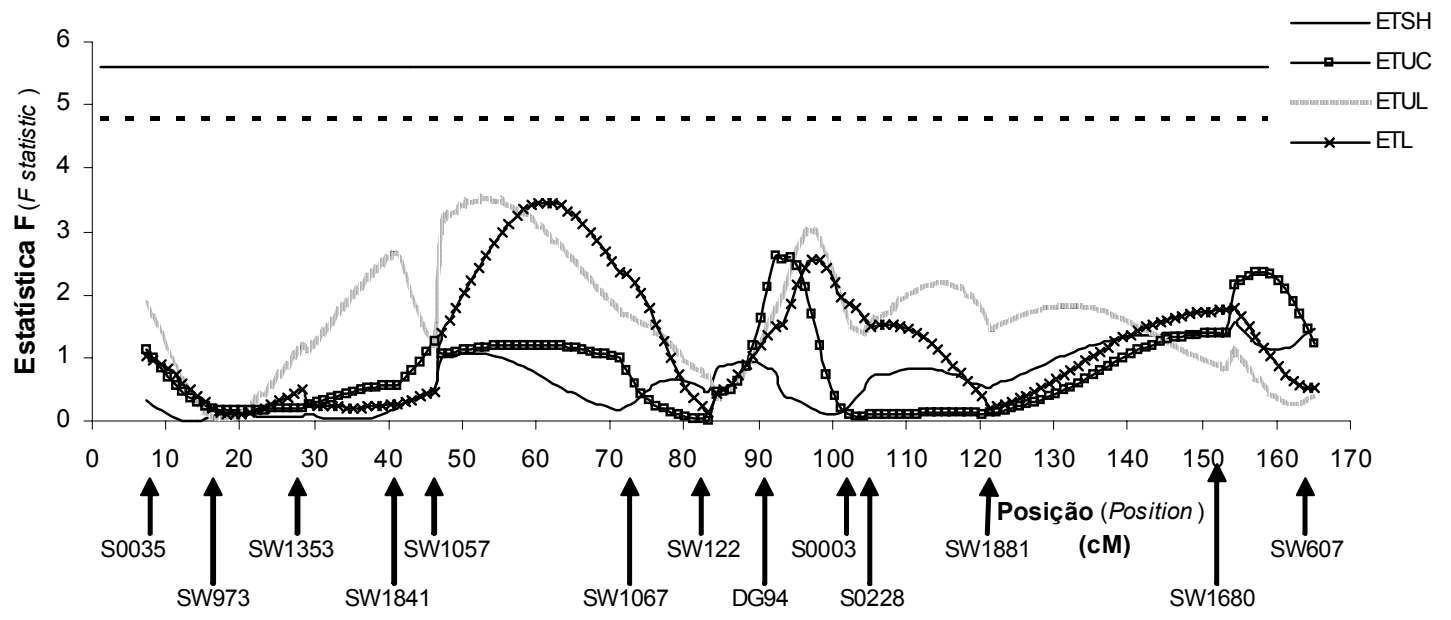

Figura 2 - Estimativas da estatística F para as características de espessura de toucinho ETSH, ETUC, ETUL e ETL. As linhas horizontais indicam os níveis de significância ao longo do cromossomo para QTL significativo $(5 \%$ = linha contínua) e QTL sugestivo $(10 \%=$ linha tracejada $)$.

Figure 2 - Estimates of F statistic for backfat thickness: ETSH, ETUC, ETUL and ETL: The horizontal lines indicate the levels of significance along the chromosome for significant QTL (5\% = continuous line) and suggestive QTL (10\% = dotted line). 


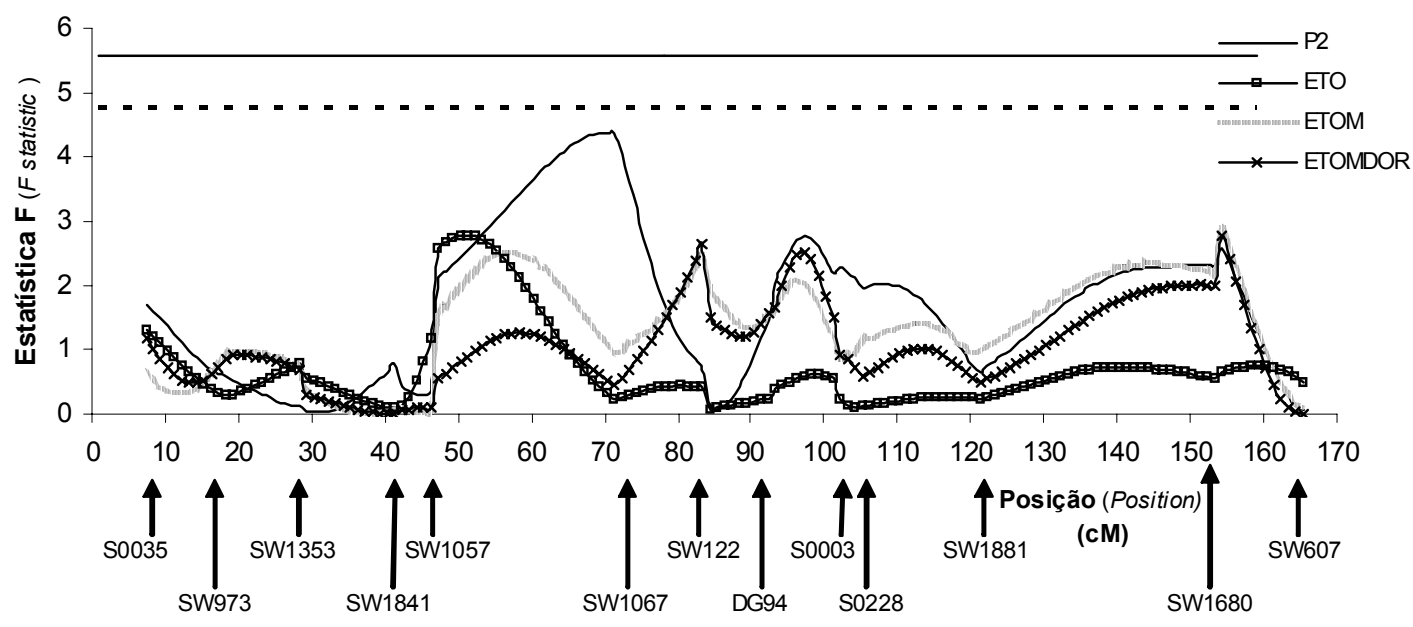

Figura 3 - Estimativas da estatística F para as características de espessura de toucinho P2, ETO, ETOM e ETOMDOR. As linhas horizontais indicam os níveis de significância ao longo do cromossomo para QTL significativo $(5 \%$ = linha contínua) e QTL sugestivo $(10 \%=$ linha tracejada $)$.

Figure 3 - Estimates of F statistic for backfat thickness: P2, ETO, ETOM and ETOMDOR. The horizontal lines indicate the levels of significance along the chromosome for significant QTL (5\% = continuous line) and suggestive $Q T L(10 \%=$ dotted line $)$.

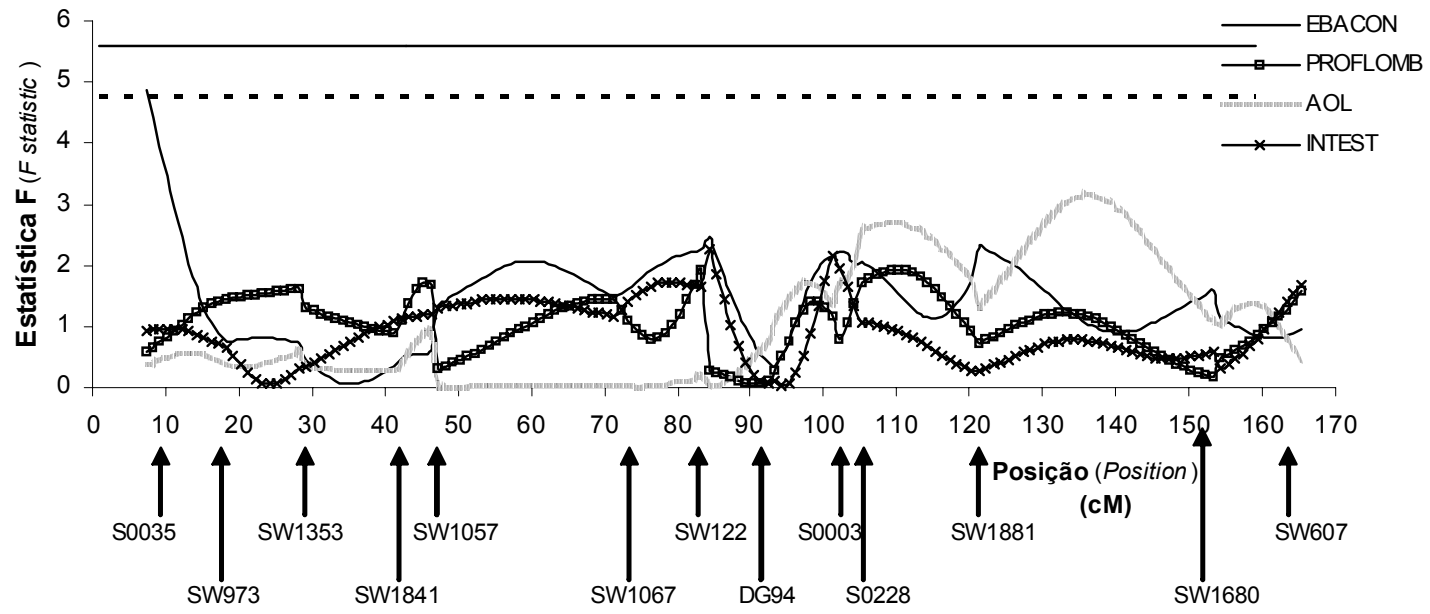

Figura 4 - Estimativas da estatística F para as características espessura de bacon (EBACON), profundidade de lombo (PROFLOMB), área de olho-de-lombo (AOL) e comprimento de intestino (INTEST). As linhas horizontais indicam os níveis de significância ao longo do cromossomo para QTL significativo $(5 \%=$ linha contínua) e QTL sugestivo (10\% = linha tracejada).

Figure 4 - Estimates of F statistic for the traits: EBACON - bacon depth; PROFLOMB - loin depth; AOL - loin eye area and INTEST - intestine length. The horizontal lines indicate the levels of significance along the chromosome for significant QTL $(5 \%=$ continuous line) and suggestive QTL $(10 \%=$ dotted line $)$.

em que não foram detectados QTLs, e aqueles da população parental dos demais estudos, nos quais foram encontrados QTLs em vários cromossomos.

Quanto às características de espessura de toucinho medidas na região dorso-lombar (ETSH, ETUC, ETUL e ETL) (Tabela 3 e Figura 2) e às demais espessuras de toucinho(P2,ETO, ETOMeETOMDOR)(Tabela3 eFigura 3), nenhuma apresentou QTL significativo ou sugestivo.

Embora não tenham sido encontrados QTLs significati$\operatorname{vos}(\mathrm{P}<0,05)$ ou sugestivos $(\mathrm{P}<0,10)$ para as diferentes medidas de espessura de toucinho neste estudo (Figuras 2 e 3 ),
QTLs significativos para esta característica foram encontrados por Óvilo et al. (2000), no cromossomo 6, por Rattink et al. (2000), nos cromossomos 2 e 7, por Harlizius et al. (2000), no cromossomo X, Walling et al. (2000), no cromossomo 4, e de Koning et al. (2001), nos cromossomos 2, 7, 14 e X. É importante ressaltar que de Koning et al. (2001) realizaram análises envolvendo herança mendeliana e também não mendeliana ("imprint").

Considerando os resultados encontrados por diferentes autores, evidencia-se novamente que a utilização das informações obtidas a partir do mapeamento de QTLs em 


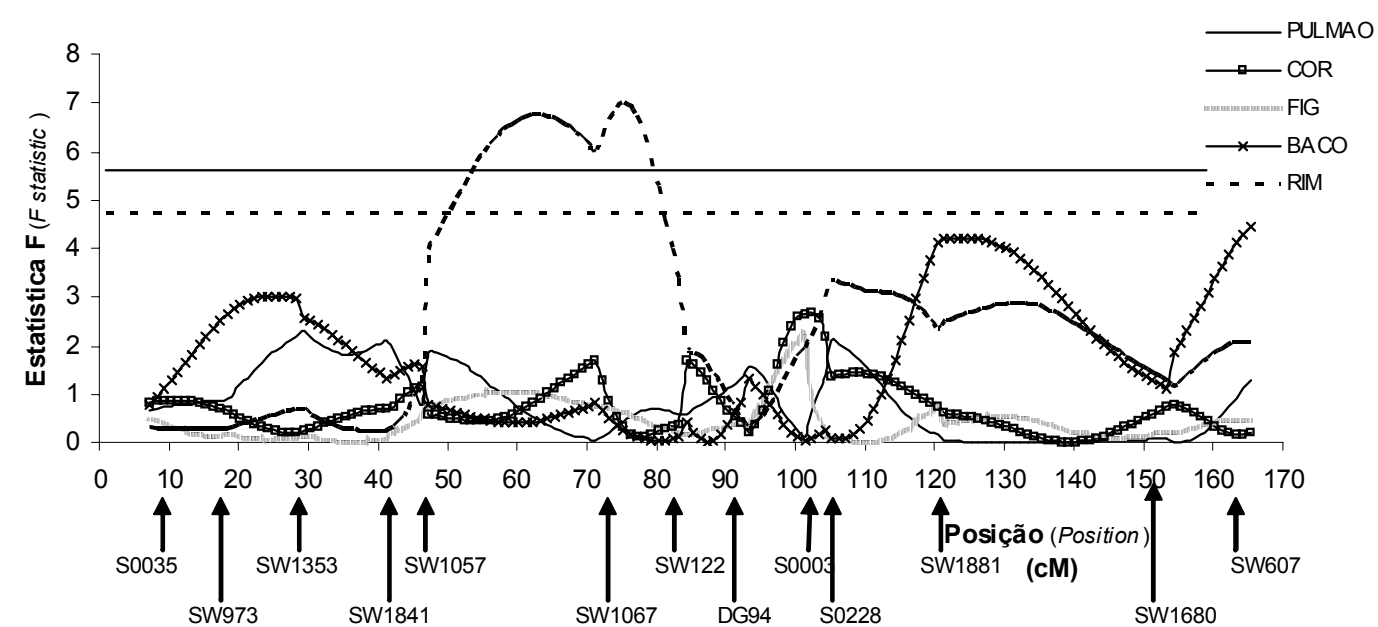

Figura 5 - Estimativas da estatística F para peso de rim (RIM), pulmão (PULMAO), coração (COR), fígado (FIG) e baço (BACO). As linhas horizontais indicam os níveis de significância ao longo do cromossomo para QTL significativo $(5 \%=$ linha contínua) e QTL sugestivo $(10 \%=$ linha tracejada).

Figure 5 - Estimates of F statistic for the traits: PULMAO - lungs weight; COR - heart weight; FIG - liver weight; BACO - kidney weight e RIM - spleen weight. The horizontal lines indicate the levels of significance along the chromosome for significant QTL $(5 \%=$ continuous line) and suggestive QTL $(10 \%$ $=$ dotted line).

outras populações, diferentes daquelas nas quais foram obtidos os resultados, não deve ser feita de forma direta. Deve-se primeiramente buscar validar estes QTLs na população que se pretende trabalhar, pois o QTL detectado pode ter seu alelo de interesse na raça não comercial ou pode não estar em fase de desequilíbrio de ligação com o marcador.

No entanto, ao analisar o comportamento da curva da estatística F para espessura de toucinho, ao longo do cromossomo (Figura 2), verifica-se tendência de coincidência de picos em algumas regiões. Os maiores picos para $\operatorname{ETUL}\left(\mathrm{F}_{\max }=3,50 ; 53 \mathrm{cM}\right)$ e ETL $\left(\mathrm{F}_{\text {max }}=3,46 ; 61 \mathrm{cM}\right)$ estão localizados próximos, sugerindo que este loco pode estar atuando em ambas as características. Comportamento semelhante é apresentado em outra região cromossômica: os picos de ETUC ( $\left.\mathrm{F}_{\max }=2,62\right)$, ETUL e ETL apresentam-se próximose bem definidos na região de 95 a $100 \mathrm{cM}$.

Além das regiões cromossômicas destacadas na Figura 2, podem ser observadas na Figura 3 duas outras regiões com coincidência de picos para espessura de toucinho, uma em $154 \mathrm{cM}$, com os picos de ETOM ( $\left.\mathrm{F}_{\max }=2,91\right)$, ETOMDOR $\left(\mathrm{F}_{\max }=2,76\right)$ e $\mathrm{P} 2$, e outra em $83 \mathrm{cM}$, com picos sugerindo QTLs responsáveis por variações para estas características.

Estes resultados de comportamento similar da estatística $\mathrm{F}$ (Figuras 2 e 3 ) sugerem que, embora medidas em regiões diferentes, as características de espessura de toucinho podem estar sob influência dos mesmos locos.

A espessura de toucinho P2 (Figura 3) apresentou um pico $\left(\mathrm{F}_{\max }=4,38\right)$ a $70 \mathrm{cM}$. Embora não seja um QTL sugestivo $(\mathrm{P}>0,10)$, com o aumento da densidade de marcadores na região de 50 a $70 \mathrm{cM}$, pode-se confirmar se seria um QTL ou uma associação falso-positiva.
QTL sugestivo $(\mathrm{P}<0,10)$ foi encontrado para espessura de bacon (EBACON) ( $\left.\mathrm{F}_{\max }=4,88\right)$, localizado na posição $7 \mathrm{cM}$ (Figura 4), mas este pico pode ser em função da ausência de marcadores na extremidade do cromossomo, uma vez que a posição deste QTL coincide com a localização do primeiro marcador S0035, tornando a estimação do QTL imprecisa, por não ter marcadores flanqueando sua provável posição. Deve-se ressaltar que, na detecção de QTL (posição e efeito), deve-se ter marcadores flanqueando sua provável posição para que a estimação seja mais precisa. Pode tratar-se de um falso QTL, cujo pico do valor $\mathrm{F}$ foi influenciado por não haver outros marcadores posicionados à extremidade do cromossomo. O marcador inicialmente posicionado na posição $0 \mathrm{cM}$ não apresentou polimorfismo e, então, não foi incluído no grupo de marcadores genotipados.

Não foram encontrados QTLs significativos para profundidade de lombo (PROFLOMB) $\left(\mathrm{F}_{\max }=1,93\right)$, área de olho-de-lombo (AOL) $\left(\mathrm{F}_{\max }=3,15\right)$ e comprimento de intestino (INSTEST) $\left(\mathrm{F}_{\max }=2,25\right)$. Diferentemente do resultado obtido nesse trabalho, Óvilo et al. (2000) encontraram QTL significativo para AOL no cromossomo $6(113 \mathrm{cM})$.

Constata-se na Tabela 3 e na Figura 5 que a característica peso de rim (RIM) apresentou $F_{\max }=6,99$ significativo $(\mathrm{P}<0,05)$, indicando haver um QTL na posição $68 \mathrm{cM}$ do cromossomo 6 suíno influenciando a variação fenotípica desta característica. Não foram encontrados QTLs significativos para pesos de pulmão (PULMAO) $\left(\mathrm{F}_{\max }=2,33\right)$, coração (COR) $\left(\mathrm{F}_{\max }=2,67\right)$, fígado (FIG) $\left(\mathrm{F}_{\max }=2,20\right) \mathrm{e}$ baço (BACO) $\left(\mathrm{F}_{\max }=4,45\right)$.

Não foram encontrados QTLs para BACO, COR, FIG e PULMAO (Figura 5). Estes resultados são semelhantes aos 
obtidos por Anderson-Eklund et al. (1998), que também não encontraram QTL significativo para pesos de coração e de baço, mas encontraram QTL significativo para peso do fígado. A característica RIM apresentou QTL significativo, o que difere dos resultados descritos por AndersonEklund et al. (1998), que não encontraram QTL significativo para esta característica.

\section{Conclusões}

Existe um QTL que influencia o peso do rim no cromossomo 6 de suínos.

Há evidência de QTLs influenciando as características comprimento de carcaça pelo método brasileiro e espessura de bacon.

As regiões em que foram encontrados QTLs sugestivos devem ser mais investigadas para se confirmar a presença destes QTLs.

\section{Agradecimento}

Ao CNPq, à CAPES e à FAPEMIG, pelo auxílio financeiro que possibilitou a realização deste trabalho.

Ao Dr. Max F. Rothschild, coordenador do Projeto Norte-Americano de Mapeamento Genômico de Suínos, pela doação dos primers de microssatélites.

\section{Literatura Citada}

ANDERSSON, L.; HALEY, C.S.; ELLEGREN, H. et al. Genetic mapping of quantitative trait loci for growth and fatness in pigs. Science, v.263, n.5154, p.1771-1774, 1994

ANDERSSON-EKLUND, L.; MARKLUND, L.; LUNDSTRÖM, K. et al. Mapping quantitative trait loci for carcass and meat quality traits in a Wild Boar x Large White intercross. Journal of Animal Science, v.76, n.3, p.694-700, 1998

BIDANEL, J.P.; MILAN, D.; IANNUCCELLI, N. et al. Detection of quantitative trait loci for growth and fatness in pigs. Genetic Selection Evolution, v.33, n.3, p.289-309, 2001

CHURCHILL, G.A.; DOERGE, R.W. Empirical threshold values for quantitative trait mapping. Genetics, v.138, n.3, p.963971,1994

de KONING, D.J.; JANSS, L.L.G.; RATTINK, A.P. et al. Detection of quantitative trait loci for backfat thickness and intramuscular fat content in pigs (Sus scrofa). Genetics, v. 152, n.4, p. $1679-1690,1999$

de KONING, D.J.; RATTINK, A.P.; HARLIZIUS, B. et al. Detection and characterization of quantitative trait loci for growth and reproduction traits in pigs. Livestock Production Science, v.72, n.3, p.185-198, 2001.

HALEY, C.S.; KNOTT, S.A.; ELSEN, J.M. Mapping quantitative trait loci in crosses between outbred lines using least squares. Genetics, v.136, n.3, p.1195-1207, 1994.
HARLIZIUS, B.; RATTINK, P.; de KONING, D.J. et al. The X chromosome harbors quantitative trait loci for backfat thickness and intramuscular fat content in pigs. Mammalian Genome, v. 11, n.9, p. $800-802,2000$.

KAPPES, S.M. Utilization of gene mapping information in livestock animals. Theriogenology, v.51, n.1, p.135-147, 1999.

MALEK, M.; DEKKERS, C.M.J.; LEE, H.K. et al. A molecular genome scan analysis to identify chromosomal regions influencing economic traits in the pig. I. Growth and body composition. Mammalian Genome, v.12, n.8, p.630-636, 2001.

NEZER, C.; MOREAU, L.; BROUWERS, B. et al. An imprinted QTL with major effect on muscle mass and fat deposition maps to the IGF2 locus in pigs. Nature Genetics, v.21, n.2, p.155$156,1999$.

NEZER, C.; MOREAU, L.; WAGENAAR, D. et al. Results of a whole genome scan targeting QTL for growth and carcass traits in a Piétrain $x$ Large White intercross. Genetic Selection Evolution, v.34, p.371-387, 2002.

ÓVILO, C.; PEREZ-ENCIZO, M.; BARRAGÁN, C. et al. A QTL for intramuscular fat and backfat thickness is located on porcine chromosome 6. Mammalian Genome, v.11, n.8, p.344-346, 2000.

RATTINK, A.P.; KONING, D.J.; FAIVRE, M. et al. Fine mapping and imprinting analysis for fatness trait QTLs in pigs. Mammalian Genome, v.11, n.8, p.656-661, 2000.

ROHRER, G.A. Identification of quantitative trait loci affecting birth characters and accumulation of back fat and weight in Meishan-White composit resource population. Journal of Animal Science, v.78, n.10, p.2547-2553, 2000.

ROHRER, G.A.; KEELE, J.W. Identification of quantitative trait loci affecting carcass composition in swine: II - Muscling and wholesale product yield traits. Journal of Animal Science, v.76, n.9, p.2255-2262, 1998.

ROSLIN INSTITUTE. [2003]. Pig genome mapping. Disponível em: <http://www.projects.roslin.ac.uk> Acesso em: 15/01/03.

ROTHSCHILD, M.F. [2003]. U.S. Pig gene mapping coordination program. Disponível em: <http://www.genome.iastate.edu/pig> Acesso em: 20/01/03.

ROTHSCHILD, M.F.; LIU, H.C.; TUGGLE, C.K. et al. Analysis of pig chromosome 7 genetic markers for growth and carcass performance traits. Journal of Animal Breeding and Genetics, v.112, n.5, p.341-348, 1995.

STATISTICAL ANALYSIS SYSTEM - SAS. SAS/STAT ${ }^{\circledR}$ (User's guide. version 6. 4.ed. Cary: 1990. 117p.

SEATON, G.; HALEY, C.S.; KNOTT, S.A. et al. QTL express: mapping quantitative trait loci in simple and complex pedigrees. Bioinformatics, v.18, n.2, p.339-340, 2002.

WALLING, G.A.; VISSCHER, P.M.; ANDERSSON, L. et al. Combined analyses of data from quantitative trait loci mapping studies: chromosome 4 effects on porcine growth and fatness. Genetics, n.3, v. 155 , p.1369-1378, 2000

WANG L.; YU, T.-P.; TUGGLE, C.K. et al. A direct search for quantitative trait loci on chromosomes 4 and 7 in pigs. Journal of Animal Science, v.76, n.10, p.2560-2567, 1998

YU, T.P.; WANG, L.; TUGGLE, C.K. et al. Mapping fatness and growth on pig chromosome 13: a search in the region close to the pig PIT1 gene. Journal of Animal Breeding and Genetics, v.16, n.4, p.269-280, 1999. 